\title{
The effect of Process Parameters on Material Removal Rate in Drilling of Al 6061-SiC composite
}

\author{
Deepak $D .{ }^{1^{*}}$ and Rajendra $B .{ }^{2}$ \\ ${ }^{1}$ Department of Mechanical and Manufacturing Engineering, Manipal Institute of Technology, \\ Manipal Academy of Higher Education, Manipal - Karnataka-576104, INDIA \\ ${ }^{2}$ Centre for Applied Sciences, Manipal Institute of Technology, Manipal Academy of Higher \\ Education, Manipal - Karnataka-576104, INDIA
}

\begin{abstract}
This study investigates the effect of process parameters such as diameter of drill, cutting velocity, feed rate and coolant supply on material removal rate while drilling of $\mathrm{Al}-\mathrm{SiC}$ composite. Sample specimens are prepared by stir-casting method and experiments are designed using Taguchi's L9 orthogonal array. Response data is analysed using $\mathrm{S} / \mathrm{N}$ ratio and significant process parameters are identified using Analysis of Variance (ANOVA). Study shows that drill diameter, followed by feed rate are found to be the most significant factors which influence MRR.
\end{abstract}

Keywords: Taguchi method, ANOVA, S/N ratio, Al6061-SiC

\section{Introduction}

Metal matrix composites (MMC) possess superior quality compared to metals. The strength-to-weight ratio and the strength exhibited by such materials make them suitable for wide range of applications like cylinder liners, structural components of landing gear of aircraft and radio frequency quadrupoles etc. Aluminium MMCs are used for various applications in aircraft, aerospace, automobile industries. Often these composite materials are generally reinforced with particles of Silicon Carbide (SiC) and Aluminium Oxide (A12O3), etc. Tamer Ozben et al. [1] studied the mechanical properties of $5 \%-15 \mathrm{wt} \%$ silicon carbide particle (SiC-p) reinforced aluminium MMC. It was observed that increase of reinforcement element produced better impact strength and hardness. Drilling is the most commonly performed machining operation during fabrication and assembly process. The quality of hole produced depends upon diameter of the drill, speed, feed rate and coolant supply. The quality of hole is measured by dimensional accuracy and surface finish. In order to obtain the best drill quality, selection of appropriate process settings is important. There are cited literatures pertaining to machining and mechanical properties of various MMC. Habibur Rahman et al. [2] found that that the hardness, tensile strength and wear resistance of $\mathrm{Al}-\mathrm{SiC}$ composite increased with increase in composition of $\mathrm{SiC}$. The influence of the feed, speed and point angle on tool wear, surface finish for various samples of Al-SiC composites was investigated by Shrinivas Jadhav et al. [3]. It was observed that

\footnotetext{
*Corresponding author: raj.beedu@manipal.edu
} 
higher percentage of $\mathrm{SiC}$ resulted in faster tool wear. The experimental evaluation of thrust force on drilling of Al-2219/B4C/Gr composite was made by Ravindranath et al.[4]. The feed rate was found to drastically increase the thrust force for mono-alloy and the addition of graphite resulted in reducing the thrust force and surface roughness. The mechanism of failure of a composite material is complex in nature which require rich set of experiments. Hence statistical tools are generally used to reduce number of experiments in selection of optimum machining parameters. Priyank et al.[5] used grey relational analysis to optimise the drilling parameters in which feed rate was found to be the most significant factor influencing the responses. Similar results were also observed by Kumar Abhishek et al. [6] using principle component analysis. Reinforcement of B4C into Al-7XXX composite showed that composition and feed rate were significant parameters which affected the trust force and torque [7]. Genetic Algorithm method was adopted by Dhawamani et al. [8] to study the effect of drilling parameters on the tool wear and surface finish of work piece. Metin Kok et al. [9] studied the effect of drilling Al/A12O3 composite on surface finish and tool life and optimised the process parameters such as composition, drill speed, drill diameters for obtaining higher material removal rate. The present work investigates the effect of various drilling parameters on Al-6061 composite with various percentage of $\mathrm{SiC}$ particles on MRR.

\section{Materials and methods}

\subsection{Preparation of Al/SiCp MMC}

The work-piece is prepared by stir-casting method. 40 grams of $\mathrm{SiC}$ particles having mesh size 170 mesh is thoroughly mixed with 20 grams of fly ash. This mixture is pre-heated to $650^{\circ} \mathrm{C}$. The addition of fly-ash prevents the formation of $\mathrm{Al}_{4} \mathrm{C}_{3}$. Al-6061 (960 gram) material is melted in a crucible which was maintained at a temperature of $850^{\circ} \mathrm{C}$. The reinforcements in the form of powder is mixed with molten metal and distributed uniformly by stir casting. The molten metal is poured into pre-heated (at $200^{\circ} \mathrm{C}$ ) metal mould and allowed for cooling to room temperature. Figure 1 shows the specimen preparation process.

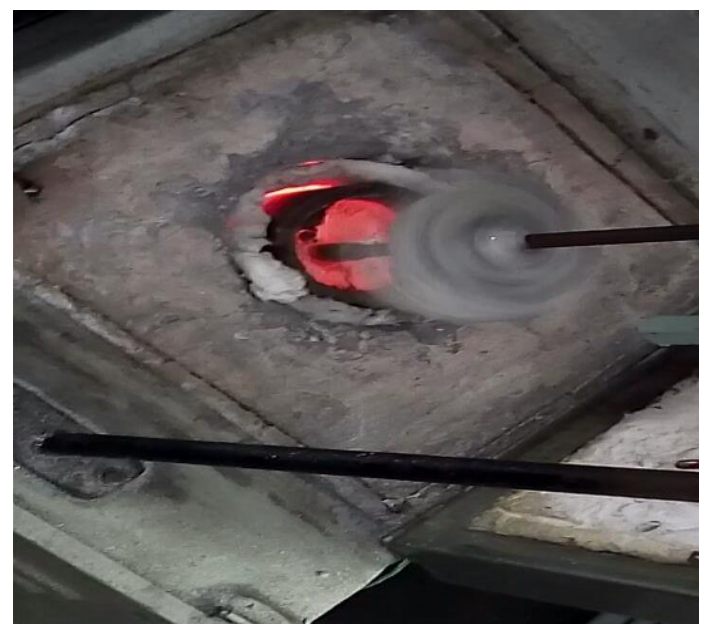

Fig. 1. Specimen preparation process 


\subsection{Experimental set up}

Experimental work is carried out using vertical machining centre (Make: AMS-SPARK). The machine is fitted with disc type tool changing system for 6 tools with table movement of 300x250x250 mm in X, Y and Z directions respectively. Figure 2 shows the experimental set-up used in the present work. The cutting tool used is high speed steel.

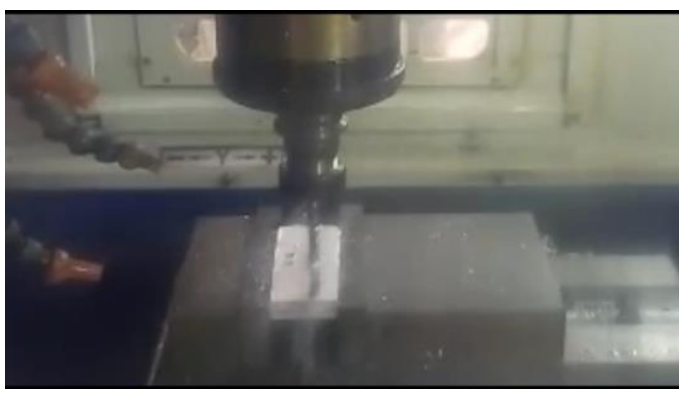

Fig. 2. Experimental setup

\subsection{Experimental design}

The experimental study involves 4 control factors of each 3 levels. Since, full factorial experimental design requires 81 runs for the study, Taguchi's L 9 orthogonal array is chosen with 2 replications. The response parameters of the study are material removal rate which is calculated based on the weight loss method during experiments. Table 1 shows the response data obtained corresponding to various experimental conditions. Table 2 shows the parameter and their levels chosen for the study.

Table 1. Experimental design and corresponding MRR

\begin{tabular}{|c|c|c|c|c|c|c|c|c|c|c|}
\hline \multirow{2}{*}{ Run } & \multicolumn{3}{|c|}{ Parameters } & \multicolumn{2}{c|}{$0 \% \mathrm{SiC}$} & \multicolumn{2}{c|}{$2 \% \mathrm{SiC}$} & \multicolumn{2}{c|}{$4 \% \mathrm{SiC}$} \\
\cline { 2 - 11 } & $\mathrm{A}$ & $\mathrm{B}$ & $\mathrm{C}$ & $\mathrm{D}$ & Trial-1 & Trial-2 & Trial-1 & Trial-2 & Trial-1 & Trial-2 \\
\hline 1 & 1 & 1 & 1 & 1 & 0.022 & 0.023 & 0.023 & 0.025 & 0.026 & 0.022 \\
\hline 2 & 1 & 2 & 2 & 2 & 0.037 & 0.034 & 0.033 & 0.03 & 0.040 & 0.042 \\
\hline 3 & 1 & 3 & 3 & 3 & 0.057 & 0.059 & 0.059 & 0.061 & 0.058 & 0.06 \\
\hline 4 & 2 & 1 & 2 & 3 & 0.070 & 0.072 & 0.058 & 0.062 & 0.067 & 0.07 \\
\hline 5 & 2 & 2 & 3 & 1 & 0.104 & 0.101 & 0.095 & 0.100 & 0.105 & 0.103 \\
\hline 6 & 2 & 3 & 1 & 2 & 0.038 & 0.035 & 0.037 & 0.035 & 0.040 & 0.043 \\
\hline 7 & 3 & 1 & 3 & 2 & 0.165 & 0.160 & 0.132 & 0.128 & 0.176 & 0.178 \\
\hline 8 & 3 & 2 & 1 & 3 & 0.060 & 0.057 & 0.061 & 0.059 & 0.066 & 0.06 \\
\hline 9 & 3 & 3 & 2 & 1 & 0.093 & 0.095 & 0.120 & 0.125 & 0.120 & 0.116 \\
\hline
\end{tabular}


Table 2. Process parameters and their levels

\begin{tabular}{|l|c|c|c|c|}
\hline \multicolumn{1}{|c|}{ Parameter } & Code & Level 1 & Level 2 & Level 3 \\
\hline Drill Diameter mm & A & 06 & 08 & 10 \\
\hline Cutting speed m/min & B & 50 & 80 & 100 \\
\hline Feed rate m/min & C & 0.04 & 0.08 & 0.12 \\
\hline Coolant flow rate ml/s & D & 0 & 62 & 312 \\
\hline
\end{tabular}

\section{Results and discussion}

Table 2 shows the MRR obtained for different experimental conditions which are replicated twice. The response data thus obtained is subjected to $\mathrm{S} / \mathrm{N}$ ratio analysis with higher the better criteria. The figure 3, 4 and 5 shows the average $\mathrm{S} / \mathrm{N}$ ratio of samples with various compositions of $\mathrm{SiC}$. The effect of operating parameters is discussed in the following sections.

\subsection{The effect of drill diameter}

Figure 3-5 shows the effect of drill diameter on MRR obtained for work-piece with 0, 2 and $4 \% \mathrm{SiC}$ respectively. It is observed that, the mean $\mathrm{S} / \mathrm{N}$ ratio of MRR is linearly increasing with increase in diameter of the drilled hole. This is due to the fact that, tool having larger diameter removes more material per revolution i.e., the volume of material removal is proportional to proportional to $\pi \mathrm{D}^{2} \mathrm{f} / 4 \mathrm{~mm}^{3} / \mathrm{min}$, where $\mathrm{D}$ is the diameter of drill bit $(\mathrm{mm})$ and $\mathrm{f}$ is the feed rate $(\mathrm{mm} / \mathrm{min})$. Hence it is seen that, increase in drill diameter increases the MRR. ANOVA values shown in table 3-5 indicate that the drill diameter is the most significant factor influencing MRR with percentage contribution $49 \%$ to $54 \%$ for different samples.

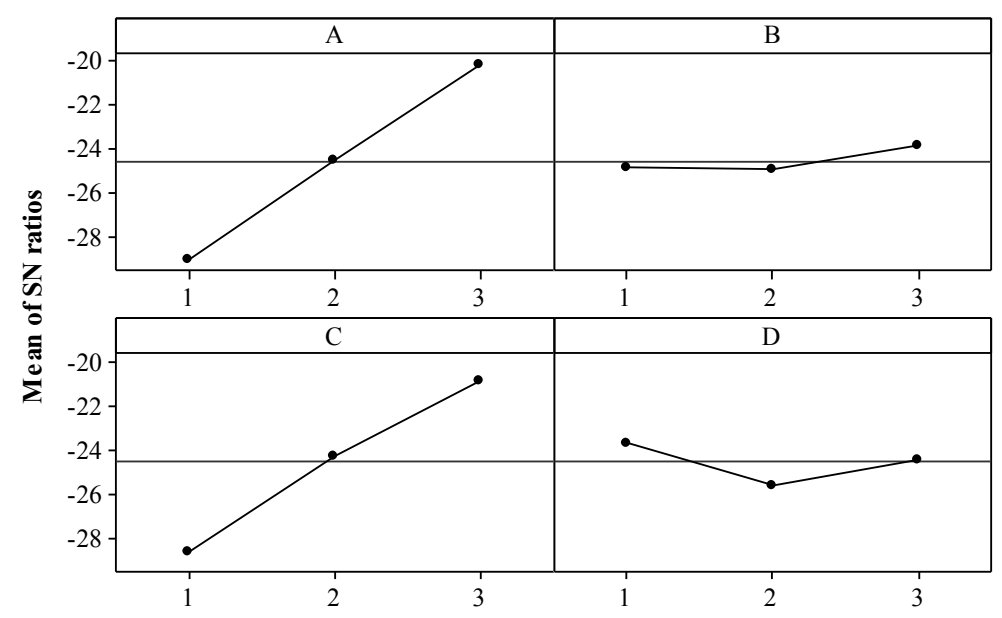

Signal-to-noise: Larger is better

Fig. 3. The effect of process parameters on MRR for Al-6061 without $\mathrm{SiC}$ 


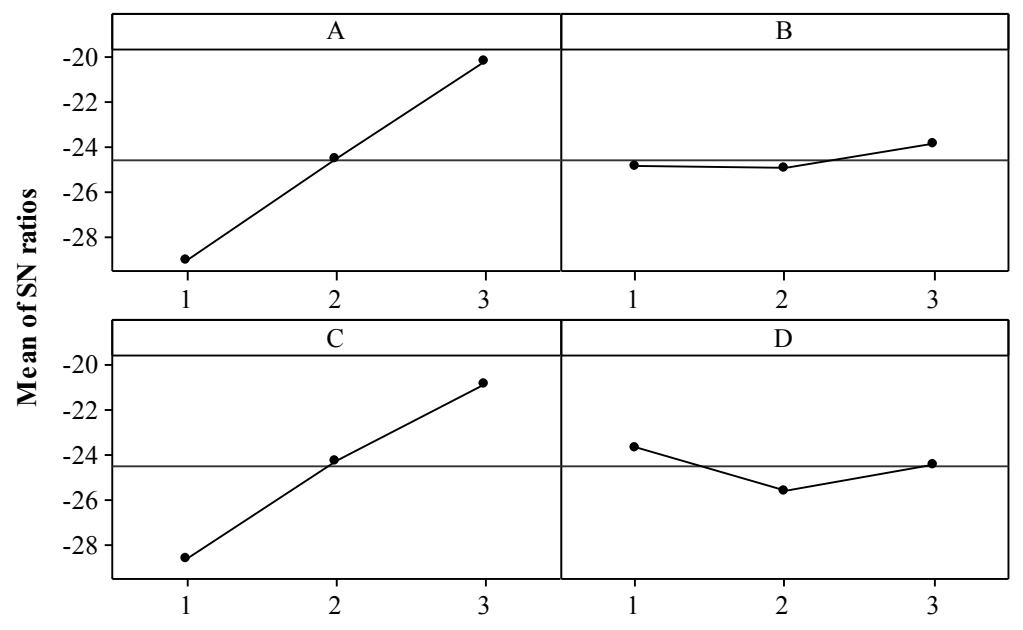

Signal-to-noise: Larger is better

Fig. 4. The effect of process parameters on MRR for Al-6061 with $2 \% \mathrm{SiC}$



Signal-to-noise: Larger is better

Fig. 5. The effect of process parameters on MRR for Al-6061 with $4 \% \mathrm{SiC}$

\subsection{The effect of cutting velocity}

Figure 3, $4 \& 5$ shows the effect of cutting velocity on MRR obtained for work-piece with 0,2 and $4 \% \mathrm{SiC}$ respectively. A slight increase in MRR is observed due to increase cutting speed. However, the percentage contribution observed by the ANOVA from table 3-5 indicates that the effect of this factor is insignificant. Hence, increasing the cutting velocity did not improve the material removal rate. 


\subsection{The effect of Feed rate}

From the figure $3-5$, it is observed that increase in feed rate increases the MRR. As mentioned earlier, volume swept by the cutting tool is proportional to feed rate. Hence increase in feed rate increases the MRR. ANOVA values shown in tables 3-5 indicate that, feed rate is also most prominent parameter which influences the MRR. The contribution of this factor varies from $42 \%$ to $50 \%$ for work-piece with different composition of $\mathrm{SiC}$ particles.

\subsection{The effect of coolant flow rate}

The effect of coolant flow rate on MRR is shown in figure 3-5. It is observed that the coolant flow has marginal influence on MRR. The function of coolant is to cool the drill bit and work-piece as well as to flush-out the chip formed. Use of coolant usually results in better the dimensional accuracy during machining and also improve the surface finish, but the present study shows its influence on rate of material removal is negligible. The influence of coolant is shown by its contribution $(0.11 \%-2.5 \%)$ as mentioned in tables $3-5$.

Table 3. ANOVA for the response data - $0 \% \mathrm{SiC}$

\begin{tabular}{|l|c|c|c|c|}
\hline Source & DF & Seq SS & Adj MS & \% Contribution \\
\hline Drill diameter & 2 & 111.49 & 55.74 & 49.25 \\
\hline Cutting velocity & 2 & 0.976 & 0.488 & 0.43 \\
\hline Feed rate & 2 & 113.64 & 56.819 & 50.19 \\
\hline Coolant supply & 2 & 0.263 & 0.1313 & 0.11 \\
\hline
\end{tabular}

Table 4. ANOVA for the response data - $2 \% \mathrm{SiC}$

\begin{tabular}{|l|l|l|l|c|}
\hline Source & DF & Seq SS & Adj MS & \% Contribution \\
\hline Drill diameter & 2 & 117.175 & 58.5875 & 54.20 \\
\hline Cutting velocity & 2 & 2.133 & 1.0666 & 0.98 \\
\hline Feed rate & 2 & 91.250 & 45.6250 & 42.21 \\
\hline Coolant supply & 2 & 5.616 & 2.8082 & 2.59 \\
\hline
\end{tabular}

Table 5. ANOVA for the response data $-4 \% \mathrm{SiC}$

\begin{tabular}{|l|l|l|l|c|}
\hline Source & DF & Seq SS & Adj MS & \% Contribution \\
\hline Drill diameter & 2 & 123.171 & 61.5855 & 54.02 \\
\hline Cutting velocity & 2 & 0.091 & 0.0457 & 0.04 \\
\hline Feed rate & 2 & 104.314 & 52.1572 & 45.75 \\
\hline Coolant supply & 2 & 0.411 & 0.2056 & 0.18 \\
\hline
\end{tabular}




\subsection{Optimisation of process parameters}

Based on the mean MRR is obtained at different levels of drill diameter, cutting velocity, feed rate and coolant supply and is shown in table $6,7 \& 8$. The maximum change in response for change in levels of the process parameter is shown as delta values in the same tables. Using delta values, the process parameters are ranked based on their order of influence on the MRR as mentioned. Further, it is observed from these tables that the maximum MRR is observed at $\mathrm{A}_{3}-\mathrm{B}_{1}-\mathrm{C}_{3}-\mathrm{D}_{2}$, i.e., at diameter drill-bit : $10 \mathrm{~mm}$, cutting velocity: $50 \mathrm{~m} / \mathrm{s}$, feed rate : $120 \mathrm{~mm} /$ minute and coolant : $62 \mathrm{ml} / \mathrm{s}$.

Table 6. Mean response - $0 \% \mathrm{SiC}$

\begin{tabular}{|l|l|l|l|l|}
\hline Level & A & B & C & D \\
\hline 1 & 0.03867 & 0.08533 & 0.03917 & 0.07300 \\
\hline 2 & 0.07000 & 0.06550 & 0.06683 & 0.07817 \\
\hline 3 & 0.10500 & 0.06283 & 0.10767 & 0.06250 \\
\hline Delta & 0.06633 & 0.02250 & 0.06850 & 0.01567 \\
\hline Rank & 1 & 4 & 2 & 3 \\
\hline
\end{tabular}

Table 7. Mean response - $2 \% \mathrm{SiC}$

\begin{tabular}{|l|l|l|l|l|}
\hline Level & $\mathrm{A}$ & $\mathrm{B}$ & $\mathrm{C}$ & $\mathrm{D}$ \\
\hline 1 & 0.03850 & 0.07133 & 0.04000 & 0.08133 \\
\hline 2 & 0.06450 & 0.06300 & 0.07133 & 0.06583 \\
\hline 3 & 0.10417 & 0.07283 & 0.09583 & 0.06000 \\
\hline Delta & 0.06567 & 0.00983 & 0.05583 & 0.02133 \\
\hline Rank & 1 & 4 & 2 & 3 \\
\hline
\end{tabular}

Table 8. Mean response - $4 \% \mathrm{SiC}$

\begin{tabular}{|l|l|l|l|l|}
\hline Level & A & B & C & D \\
\hline 1 & 0.04133 & 0.08983 & 0.04283 & 0.08200 \\
\hline 2 & 0.07133 & 0.06933 & 0.07583 & 0.08650 \\
\hline 3 & 0.11933 & 0.07283 & 0.11333 & 0.06350 \\
\hline Delta & 0.07800 & 0.02050 & 0.07050 & 0.02300 \\
\hline Rank & 1 & 4 & 2 & 3 \\
\hline
\end{tabular}




\section{Conclusions}

Following conclusion are drawn from present work.

- The influence addition of $\mathrm{SiC}$ (up-to 4\%) particles into Al-6061 on MRR is negligible.

- The most significant factor influencing MRR while drilling Al-6061 SiC composite using HSS tool is the drill diameter, followed by feed rate.

- The effect of coolant on MRR is negligible.

- Optimum settings for maximum MRR is $\mathbf{A}_{\mathbf{3}}-\mathbf{B}_{\mathbf{1}}-\mathbf{C}_{\mathbf{3}}-\mathbf{D}_{\mathbf{2}}$, i.e., at diameter drill bit : 10 $\mathrm{mm}$, cutting velocity: $50 \mathrm{~m} / \mathrm{s}$, feed rate : $120 \mathrm{~mm} /$ minute and coolant : $62 \mathrm{ml} / \mathrm{s}$ for all compositions of work material.

The author wishes to express their sincere thanks to Manipal University for providing laboratory support for this research work.

\section{References}

1. Tamer Ozben, Erol Kilickap and Orhan Cakir, Investigation of mechanical and machinability properties of SiC particle reinforced Al-MMC, Materials processing technology 198 (2008)

2. Md. Habibur Rahman, H. M. Mamun Al Rashed, Characterization of silicon carbide reinforced aluminum matrix composites, 10th International Conference on Mechanical Engineering, ICME 2013, Procedia Engineering pp. 103 - 109, 90 (2014)

3. Shrinivas Jadhav, Jaywant Sankpal, Mukesh Chaudhari and Nilesh Patil, A review on drilling of metal matrix composites, International Journal of Current Engineering and Technology, pp. 1-7 (2016)

4. V M Ravindranath, G S Shiva Shankar, S Basavarajappa, R Suresh, Effect of cutting parameters on thrust force and surface roughness in drilling of Al-2219/B4C/Gr metal matrix composites, IOP Conf. Series: Materials Science and Engineering149 (2016)

5. D. Priyank, K. Arun, P. Venkata Ramaiah, Optimization of process parameters in drilling of hybrid aluminium metal matrix composite", International Journal of Innovative Research in Science, Engineering and Technology , 5 (2016)

6. Kumar Abhishek, Vikas Sonkar, Saurav Datta, Siba Sankar Mahapatra, "Optimization in drilling of MMC composites- A case research", Journal of Basic and Applied Engineering Research, 1(2014)

7. Ahmet Tapkesen, Kenan Kütükde, Optimisation of the drilling parameters for the cutting process in $\mathrm{B} 4 \mathrm{C}$ reinforced Al-7XXX series alloys based on Taguchi method, Materials and technology, pp. 169-176, 47 (2013)

8. C Dhawamani and $\mathrm{T}$ Alwarsami, Optimisation of machining parameters for $\mathrm{Al} / \mathrm{SiC}$ composite using genetic algorithm, International Conference on Modelling Optimisation and computing, Procedia Engineering 38 (2012)

9. Metin Kok, A study on the machinability of $\mathrm{Al} 2 \mathrm{O} 3$ particle reinforced aluminium alloy composite, 11th Int. Inorganic Bonded Fibre Composite Conference, Mandrid (2008) 